\title{
Human fear conditioning: from neuroscience to the clinic
}

\author{
M.A. Fullana ${ }^{1,2}$; J. E. Dunsmoor ${ }^{3}$; K.R.J. Schruers ${ }^{4,5}$; H. S. Savage ${ }^{6}$; D. R. Bach ${ }^{7,8}$; B. J. Harrison ${ }^{6}$
}

${ }^{1}$ Adult Psychiatry and Psychology Department, Institute of Neurosciences, Hospital Clinic, Barcelona, Spain.

2 Institut d'Investigacions Biomèdiques August Pi i Sunyer, CIBERSAM, Barcelona, Spain.

3 Department of Psychiatry, University of Texas at Austin, Austin, Texas.

${ }^{4}$ Department of Psychiatry and Neuropsychology, Maastricht University, The Netherlands.

${ }^{5}$ Department of Health Psychology, University of Leuven, Belgium

${ }^{6}$ Melbourne Neuropsychiatry Centre, Department of Psychiatry, The University of Melbourne \& Melbourne Health, Victoria, Australia.

${ }^{7}$ Wellcome Centre for Human Neuroimaging and Max Planck UCL Centre for Computational Psychiatry and Ageing Research, University College London, London, UK

${ }^{8}$ Computational Psychiatry Research, Department of Psychiatry, Psychotherapy and Psychosomatics, University of Zurich, Zurich, Switzerland.

\section{Correspondence to:}

Dr. M. A. Fullana. Institute of Neurosciences, Hospital Clinic, Barcelona, Spain.

Rossello, 140, 08036, Barcelona, Spain. Tel:+34 932275494. E-mail: mafullana@ clinic.cat. 


\begin{abstract}
Both clinicians and neuroscientists have been long interested in the topic of fear conditioning, with recent advances in neuroscience, in particular, igniting a shared interest in further translational between these domains. Here, we review some historical aspects of this relationship and the progress that has been made in translating the neuroscientific study of fear conditioning to the conceptualization and treatment of mental disorders, especially anxiety-related disorders. We also address some conceptual and methodological challenges faced by this research, and offer some suggestions to support future progress in the field.
\end{abstract} Keywords: fear conditioning, neuroscience, anxiety 


\section{INTRODUCTION}

When in 1920, John B. Watson and Rosalie Rayner conditioned a young child who would become known as "Little Albert", they could not have imagined the extraordinary impact that their experiment would have in our current conceptualization of anxiety-related disorders, almost a century later. Over the past two decades, in particular, this legacy has been strengthened by the 'happy marriage' between neuroscientists and clinicians interested in the topic of fear conditioning phenomena, although it must be said, love took a while to emerge. In this review, we will briefly reflect on some of the history of this relationship and the specific progress that has been made in translating the neuroscientific study of human fear conditioning models to the management and treatment of anxiety-related disorders (including panic disorder/agoraphobia; specific phobia; social anxiety disorder, SAD; generalized anxiety disorder, GAD; obsessive-compulsive disorder, OCD; and posttraumatic stress disorder, PTSD). We will also address some of the conceptual and practical challenges that have been faced during this process and will offer some suggestions for future research in the field.

\section{HOW DID WE GET HERE? FROM WATSON TO FMRI.}

Watson is considered one of the founding fathers of behaviorism as a scientific movement or paradigm. Besides introducing behaviorism, Watson's emphasis on environmental influences sharpened the focus of experimental psychology on the construct of 'learning' and on the formulation of 'laws of behavior', a focus which endured for at least three decades. During that period, experimental psychology was also heavily influenced by research in laboratory animals (Kazdin, 1978; Krasner, 1990). Research into classical (Pavlovian) conditioning processes, in particular, shaped the development of behavior modification approaches, 
including early forms of behavior therapy, until the mid-twentieth century. The initial focus of behavior therapy was in the treatment of fears and anxiety (or "neuroses"), which can be traced back to the original Pavlovian conditioning experiment on "Little Albert". In this famous experiment, the infant Albert - who initially displayed no signs of fear to a white rat, was made to fear the rat when associated with a noise of a hammer strike on a steel bar. The fear of the rat then generalized to other perceptually similar objects, such as a fluffy white beard. Although the "Little Albert" study does not conform to the ethical standards of modern behavioral research, it is considered the first laboratory demonstration of fear conditioning in a human. It also inspired an important follow-up experiment by Mary Cover Jones demonstrating effective behavior modification based on the principles of fear conditioning (Jones, 1924). In the "Little Peter" experiment, the child - who displayed signs of fear to rabbits before the experiment - learned to overcome this fear by associating the presence of rabbits with a pleasurable activity (eating candy). While Peter ate candy, the rabbit was placed closer and closer until the rabbit was eventually close enough to nibble on Peter's fingers. Considered the first controlled demonstration of counterconditioning in humans, the "Little Peter" experiment influenced the work of Wolpe and the development of behavior modification techniques, like systematic desensitization (Wolpe, 1961).

The application of learning models, including fear conditioning models, to clinical psychology, especially with application to anxiety-related disorders, thrived during a 'golden age' that lasted approximately 30 years. In the 1970s, however, the 'cognitive revolution' had come to dominate the clinical field (see Greenwood, 1999), and although fear conditioning models were developed to incorporate cognitive variables (see Mackintosh, 1974), for a number of reasons the focus on fear conditioning in mental health research declined.

In contrast, interest in fear conditioning remained stable in neuroscience and become particularly prominent in the 1980s. Although interest in the biological basis of classical 
conditioning dates back to at least Pavlov (end of the 19th century), the impetus for biological research was primarily stimulated 50 years later with Mowrer's "two-factor" theory, which merged Pavlovian and instrumental approaches. According to Mowrer, conditioned fear reduction was the main reinforcer of avoidance conditioning. By the 1950s, avoidance conditioning had become the dominant paradigm through which to examine the brain basis of fear learning. The influence of Mowrer's work, and that of his colleague Neal Miller, remained prominent until the 1980s (LeDoux, Moscarello, Sears, \& Campese, 2017). However, by this time, due to unresolved conceptual issues and inconclusive results regarding the brain basis of avoidance, most researchers interested in learning had shifted their focus to 'simpler' Pavlovian conditioning approaches.

The characterization of specific neural mechanisms of Pavlovian conditioning throughout the 1980s significantly raised the profile of conditioning research in the neuroscience realm. As a consequence of these discoveries: "fear conditioning thus became a process that is carried out by cells, synapses, and molecules in specific circuits of the nervous system" (LeDoux, 2014, p. 2873). Indeed, throughout the 1980s and 90s, rapid gains were made in mapping the neural circuits involved in various fear conditioning processes, including acquisition, extinction, generalization, cue competition effects, and contextual processes. Most notably, this research highlighted the amygdala as a primary hub in the brain's fear circuity involved in the learning and expression of conditioned defensive behavior.

By the early 1990s, the availability of functional neuroimaging techniques, including positron emission tomography (PET) and functional magnetic resonance imaging (fMRI) had begun to transform research in the fields of human cognitive and clinical neuroscience. In particular, the development of fMRI, which offered superior temporal resolution to PET, was especially relevant to expanding fear conditioning research in humans (Büchel, Morris, 
Dolan, \& Friston, 1998; Kevin S LaBar, Gatenby, Gore, LeDoux, \& Phelps, 1998). The development of this line of research, which has remained strongly influenced by animal fear conditioning models, has broadly reinforced the notion that Pavlovian conditioning processes are suited to cross-species translational research.

\section{The Brain's Extended 'Fear Circuit'}

Given the widespread interest in the neurobiology of fear conditioning, there are a number of remarkable in-depth reviews on this topic (e.g., Herry \& Johansen, 2014; LeDoux, 2000; Tovote, Fadok, \& Lüthi, 2015). Thus, we provide just a brief overview of the major neurocircuitry that is thought to be conserved across mammalian species and that has an important role in governing emotional learning processes in fear conditioning.

The predominant neurocircuitry centers on connections within and between the amygdala, hippocampus and extended areas of the medial prefrontal cortex. The amygdala is crucial for the acquisition, storage, and expression of learned fear associations through widespread connections with sensory regions, and output connections with areas involved in defensive behavior (LeDoux, 2000). The anterior cingulate cortex (prelimbic cortex in rodents), in particular has been associated with the expression of conditioned fear responses, whereas the ventromedial prefrontal cortex (infralimbic cortex in rodents) is important for inhibiting threat expression by downregulating amygdala activity. In the context of conditioning research, the ventromedial prefrontal cortex has been predominately investigated for its role in the learning, storage, and retrieval of extinction ('safety') memories (Milad \& Quirk, 2012). The hippocampus is important for forming contextual fear associations, and in contextually gating the retrieval of extinction memories (Maren, Phan, \& Liberzon, 2013). Emerging neuroscience research using pioneering fine-scale molecular 
imaging and activity-dependent neural tagging techniques is now beginning to reveal how distinct neural populations and synaptic connections within and between these regions orchestrate the balance between the expression of threat- and safety-related behaviors (Krabbe, Gründemann, \& Lüthi, 2018).

Human fMRI studies of conditioning processes have most consistently emphasized the involvement of extended medial prefrontal cortex areas in responding to conditioned fear/threat and safety signals. The anterior cingulate cortex, together with anterior insular cortex, are among the brain regions most reliably involved in human conditioned fear/threat processing, whereas the ventromedial prefrontal cortex is consistently more responsive to conditioned safety signals (Fullana et al., 2016). Translating the role of the amygdala, clearly demonstrated in rodents (LeDoux, 2000), to human fMRI has turned out to be more complicated. In the recent meta-analysis of fear conditioning fMRI studies by Fullana et al (2016), the amygdala was not identified as consistently showing tissue activity. In contrast, in patients with amygdala lesions, impaired conditioned fear acquisition has been demonstrated (Bechara et al., 1995; K S LaBar, LeDoux, Spencer, \& Phelps, 1995).

Inconsistent translation of the animal neuroscience to human neuroimaging could of course be due to a number of methodological factors that do not necessarily call into question the role of these regions in fear conditioning in humans. For instance, failure to detect amygdala activity in fMRI could be due to well-known difficulties in signal detection from this region (e.g. Weiskopf, Hutton, Josephs, \& Deichmann, 2006). Another potential explanation comes from animal neuroscience, which shows that a relatively small number of sparsely distributed neurons respond to a fear conditioned stimulus (CS+)(Reijmers, Perkins, Matsuo, \& Mayford, 2007), which could be below what is required for detecting regional activity with fMRI. Furthermore, in addition to neurons responding to the presence of a CS+, a roughly equal number respond to the absence of a CS+ (Haubensak et al., 2010). Because 
conventional fMRI applies spatial filtering ('smoothing') at a multi-voxel level, observed fMRI responses to a threat and control conditioned stimuli within the amygdala in humans might be similar. Indeed, three fMRI studies of human fear conditioning using different (multivariate) approaches and focusing on trial-by-trial activation patterns have illustrated that amygdala activity can differ between a CS+ and CS- (safety conditioned stimulus) during fear conditioning (Bach, Weiskopf, \& Dolan, 2011; Staib \& Bach, 2018; Visser, Scholte, Beemsterboer, \& Kindt, 2013).

Despite these caveats, animal and human experimental studies remain focused on understanding the contribution of this extended neural circuitry to distinct fear conditioning processes, including their clinical translation in studies of patients with anxiety-related disorders. Regarding the latter, a common observation in fMRI studies of such patient groups is that they demonstrate heightened activation of the anterior cingulate, insula, and less consistently the amygdala, in response to conditioned threats, when compared to healthy or trauma exposed control participants (Milad et al., 2009; Rougemont-Bücking et al., 2011; Suarez-Jimenez et al., 2019; Veit et al., 2002).

In fMRI studies of differential fear conditioning, patient groups have also shown reduced activity in the ventromedial prefrontal cortex to cues that signal safety. Such reductions in vmPFC activity to cues signalling safety have been observed in PTSD (Jovanovic, Kazama, Bachevalier, \& Davis, 2012; Milad et al., 2009; Rougemont-Bücking et al., 2011; Suarez-Jimenez et al., 2019), GAD (Cha et al., 2014; Via et al., 2018); and OCD (Apergis-Schoute et al., 2017; Milad et al., 2013). Reduced activation of the vmPFC during fear extinction learning was also shown to predict poorer response to exposure therapy in patients with SAD (Ball, Knapp, Paulus, \& Stein, 2017). Thus, while altered fear conditioning has long been suggested in the pathophysiology of anxiety-related disorders 
(Eysenck, 1979), it is only more recently that altered processing of conditioned safety signals has received empirical attention, especially in the neuroscientific study of such disorders (Milad \& Quirk, 2012).

Its is important to note that the (renewed) interest in translational fear conditioning models aligns well with new approaches in mental health research that aim to develop nosological classifications that focus on neural (dys)function rather than on symptoms alone, and which can be eventually linked with personalized interventions ("precision medicine") (Haro et al., 2014; Insel, 2014). In fact, some authors have noted that fear-conditioning models could be one of the best candidates for translating neuroscientific discoveries into clinical applications (Anderson \& Insel, 2006).

\section{TRANSLATING NEUROSCIENCE TO THE CLINIC}

There continue to be pioneering advances in the neuroscience of learning and memory using fear conditioning models, especially in rodents. And with technological developments—such as the use of activity-dependent neural tagging and optogenetics - the fine-scale microcircuitry within and between the amygdala, hippocampus, and medial prefrontal cortex is coming into view (Janak \& Tye, 2015; Krabbe et al., 2018; Tovote et al., 2015). But an important and highly interesting question going forward is whether and how breakthroughs in the neuroscience of fear learning ultimately contribute to our understanding of, and treatment for, mental health disorders in humans. For example, how does an understanding of the molecular underpinnings of associative fear learning in the amygdala help patients suffering with PTSD? To date, much of the translation from behavioral neuroscience in rodents to treatment of humans with mental health disorders is experimental or preclinical. Like much 
clinical translational research, there have been periods of early excitement and promise followed by periods of disappointment.

\section{Disrupting fear memories}

One route of translation concerns adapting models of memory consolidation and reconsolidation to treat mental health disorders within a critical time window, using both pharmacological and non-pharmacological approaches (Monfils \& Holmes, 2018; Schwabe, Nader, \& Pruessner, 2014). One approach is to disrupt the formation of a memory by interfering with the memory consolidation processes soon after learning (McGaugh, 2015). For example, direct injections of a protein synthesis inhibitor into the lateral amygdala can abolish the long-term expression of a conditioned fear memory in rodents (Johansen, Cain, Ostroff, \& LeDoux, 2011). But attempts to disrupt learning with less toxic drugs, like the beta-blocker propranolol, are extremely sensitive to the timing between learning and drug administration. Specifically, injection of the beta-blocker propranolol into the lateral amygdala before fear conditioning disrupts formation of a conditioned fear memory (Bush, Caparosa, Gekker, \& Ledoux, 2010), but injection immediately after conditioning does not stop the formation of a long-term fear memory (Schiff et al., 2017). This temporal regulation is important, because it suggests that attempts to stop a negative emotional memory from being formed will be thwarted if the drug is not already onboard when the experience occurs. This sensitive time window for disrupting emotional memory formation might explain why attempts to interfere with memory formation soon after a trauma have met with limited or no success (Pitman et al., 2002; Sharp, Thomas, Rosenberg, Rosenberg, \& Meyer, 2010; see also Phelps \& Hofman, 2019). From an adaptive memory framework, the propensity to retain fear associations is paramount to evolutionary survival, and hence these emotional experiences 
may be fiercely resistant to interference and forgetting (see Dunsmoor et al., 2018). But from a clinical perspective, the inability to prevent the formation of emotional memories after a negative experience renders memory modification a challenging treatment strategy.

Because blocking the formation of an emotional memory may be challenging without the use of invasive and unsafe protein synthesis inhibitors, and due to the fact that most individuals seek treatment well after negative life events or traumas, another approach is to disrupt memories after they are already formed. Reactivating an old memory can, under certain circumstances, lend the memory to becoming labile and susceptible to interference during a process known as memory reconsolidation. Invasive injections of protein synthesis inhibitors into the lateral amygdala, after memory reactivation, can effectively block the reconsolidation of a fear conditioning memory (Nader, Schafe, \& LeDoux, 2000), and this has been translated to humans with oral administration of propronolol (Kindt, Soeter, \& Vervliet, 2009.) Limited clinical work has tried to interfere with memory reconsolidation in PTSD by administering the beta-blocker propranolol shortly before memory reactivation, so that the drug is onboard at the time of memory reconsolidation. But results on improving PTSD symptoms have been mixed with some successes (Brunet et al., 2008, 2018) and some negative findings (Wood et al., 2015). A dominating concern in the memory reconsolidation literature is the tenuous effects observed without the use of invasive protein synthesis inhibitors. For instance, research using safe pharmacological approaches, like propranolol, or non-pharmacological techniques, like extinction or interference training following memory reactivation, have been inconsistent across species (e.g. Luyten \& Beckers, 2017). Furthermore, whether a consolidated fear memory is susceptible to permanent disruption (or “erasure") remains controversial (Gisquet-Verrier \& Riccio, 2018), and the conditions by which a memory is most susceptible to interference via reconsolidation updating will be challenging to control in a clinical setting (Treanor, Brown, Rissman, \& Craske, 2017). 
Moreover, even memories for single events can be expressed in different ways (subjective, physiological, etc) and each way may be linked to different neural representations. i.e., may involve a different brain system for storage and expression (Phelps \& Hofmann, 2019). However, the molecular pathways involved in consolidation and re-consolidation, spanning from neurotransmitters, intra-synaptic signaling, and translational/transcriptional mechanisms to structural changes in the extracellular matrix (Bach, Tzovara, \& Vunder, 2018; Bach et al., 2019a; Bach et al., 2019b), are under active investigation. This may provide potential for the development of new drug targets, including repurposing of human-approved compounds (Bach et al., 2019a, 2019b; Ross et al., 2017; Sartori \& Singewald, 2019). Note that we have focused here on the applications to interfering with aversive memory in anxiety-related disorders, but memory interference approaches have also been used in substance use disorders on the basis that these involve pathological reward memory (Treanor et al., 2017; Paulus et al., 2019).

\section{Strengthening extinction memories}

Because extinction is considered new learning (rather than erasure of the old memory), techniques to generally strengthen learning and memory could be levied to improve extinction-based therapies, like exposure. Thus, another method informed by the neuroscience of fear conditioning are drugs that act as putative cognitive enhancers to improve learning and memory during fear extinction training (Singewald, Schmuckermair, Whittle, Holmes, \& Ressler, 2015). One drug is d-cycloserine, a partial N-methyl-D-aspartate receptor agonist, shown in rodent studies to improve extinction memory (Davis, Ressler, Rothbaum, \& Richardson, 2006; Ledgerwood, Richardson, \& Cranney, 2005), probably through enhanced extinction memory consolidation (e.g. Ledgerwood, Richardson \& 
Cranney, 2003, Parnas, Weber \& Richardson, 2005). Administering this drug in combination with extinction training has shown some promise in well-controlled laboratory fear conditioning experiments, and there is evidence that it augments treatment for anxiety-related disorders (Hofmann, Sawyer, \& Asnaani, 2012; Rothbaum et al., 2014). However, a recent individual patient data meta-analysis concluded that d-cycloserine indeed enhances the effect of exposure-based therapy, but the effect size was modest (Mataix-Cols et al., 2017). Important to note is that none of the studies established beforehand if their participants indeed suffered from extinction (consolidation) deficits, and it might well be that this process is only hampered in a subset of patients suffering from anxiety-related disorders.

Neuroscientific methods that could reliably identify individuals with such deficits would have important clinical implications and contribute towards "precision medicine" approaches.

One pitfall of the use of a putative cognitive enhancer is that a treatment session that results in heightened (rather than reduced) fear and anxiety within-session may be preferentially remembered under a drug that enhances learning and memory, thus rendering treatment counterproductive (Litz et al., 2012; Smits et al., 2013). Thus, caution should be exercised when administering techniques that strengthen learning and memory to prevent "good" exposure therapy from going "bad" (Hofmann, Otto, Pollack, \& Smits, 2014). Further knowledge on appropriate dosages, timing, and effects of repeated administration (e.g., tolerance) are also in need of more careful laboratory study before cognitive enhancers should be widely used in combination with behavioral treatment.

There is now emerging research using non-pharmacological neurostimulation to enhance learning and memory in the context of psychiatric treatment. A treatment form that is based on knowledge of the macroscopic functional neuroanatomy of psychopathological phenomena is repetitive transcranial magnetic stimulation (rTMS). This involves placing a strong, focal magnetic field above a certain location on the skull and thus causing an electric 
field in the brain tissue below. The action radius and effect of this electrical current depend on a number of factors, including the type and orientation of the coil, distance between coil and brain and the intensity, frequency and pattern of the magnetic pulse.

rTMS is now an established treatment for depression (Lefaucheur et al., 2014) and applications in anxiety-related disorders are being investigated. Mostly, rTMS is offered as a stand-alone treatment but increasingly also combinations with psychotherapy are being explored. These combinations can take various forms. Series of rTMS sessions can be offered "in parallel" over the same time period (usually a number of weeks) in which also some form of psychotherapy takes place, or both types of treatment can be offered consecutively. The most attractive option, however, is the use of rTMS during psychotherapy sessions. Particularly exposure therapy lends itself for this option because of its proven efficacy, its highly formalized application and available knowledge on the underlying mechanisms. Several of such (relatively small) studies have been undertaken in anxiety-related disorders, with mixed results however (Chalah \& Ayache, 2019). This unclear picture is likely due to the large variation in methods between those studies regarding the type and intensity of the rTMS applied, comorbidity, medication use and the presence and type of sham condition. A way forward here lies in making use of the current insights in the mechanisms of therapy. Exposure therapy relies on extinctionbased memories and success of fear extinction is crucial for its short and long term outcome (Lange et al. 2016, 2019). The therapy effect is subserved by an inhibiting effect of the vmPFC on the amygdala. This was elegantly demonstrated in an experimental study in healthy volunteers, were the expression of conditioned fear responses was reduced by applying rTMS to the vmPFC (Raij et al.,2018). This study may guide future studies in several ways: The expression of conditioned fear responses was achieved by applying rTMS during extinction learning. This suggests that studies in patients may benefit from a design in which rTMS is applied "online", during an 
exposure therapy session rather than "offline". Further, target selection for rTMS placement was based on functional connectivity analyses. Clinical studies may also benefit from a more individual and/or disorder related target selection, based on prior connectivity analyses.

\section{"Novelty-based" approaches}

Another strategy to improve memory for extinction, over memory of the fearful experience, is to selectively enhance the consolidation of the extinction memory. One potential approach from the animal behavioral neuroscience literature involves exposing animals to novelty in limited temporal window after learning to enhance consolidation of weak memories stored in the hippocampus, a technique in line with the synaptic-tag-andcapture hypothesis (Frey \& Morris, 1997). For instance, in what is referred to as "behavioral tagging" (Moncada \& Viola, 2007), animals who undergo a poor context fear extinction session (limited time in the cage without shocks) later expressed a strong extinction memory (diminished freezing in the feared environment) if extinction was shortly followed by exposure to a novel open field (de Carvalho Myskiw, Benetti, \& Izquierdo, 2013; Menezes et al., 2015). This model has been extended to explain selective retroactive enhancement of episodic memory in humans (Dunsmoor, Murty, Davachi, \& Phelps, 2015). Whether novelty exposure improves human fear extinction memory remains to be shown, and there has been surprisingly little research attempting to translate behavioral tagging to human fear conditioning and extinction.

Importantly, animal studies show that behavioral tagging effects depend on dopamine inputs into the hippocampus (Menezes et al., 2015). Thus, behavioral tagging effects might be indirectly inferred from research using post-extinction administration of L-Dopa. That is, L-Dopa administration after extinction diminishes the renewal of fear in rats and humans 
(Haaker et al., 2013). To date, these approaches have received fairly limited attention, and much more work is needed to evaluate how they could be adapted to the clinic for treatment of anxiety-related disorders. It is also important to consider whether incorporating novelty or L-Dopa as an adjunct to improve extinction memory might inadvertently strengthen fear memory, similar to inadvertent effects seen in the use of d-cycloserine (Hofmann, Otto, Pollack, \& Smits, 2014). For this reason, the use of STC based approaches to putatively strengthen extinction memory warrants caution if applied in a clinical context. For a recent review on these and other approaches for "editing" fear memories, we refer the reader to the recent review by Phelps \& Hofmann (2019).

\section{CHALLENGES IN TRANSLATION}

\section{Conceptual challenges}

The beauty of human fear conditioning paradigms is their simplicity and possibility to translate across various mammal and non-mammal species, such that molecular and cellular knowledge garnered in other species can be leveraged for developing treatments. Nevertheless, the paradigm models only some aspects and symptoms of anxiety-related disorders.

For example, for many specific phobias, there is no consistent evidence that they emerge in the way that Watson proposed: an early traumatic experience with the to-be-feared stimulus, including actually aversive consequences to the patient. This is particularly obvious for spider phobia in north-central Europe where poisonous spiders do not exist or are rare. It is unclear what the aversive or traumatic consequence of an early spider encounter should have been for the patient. Although observing one's parent run away from a spider and shout 
in panic could possibly explain generation of spider phobia, this is not the mechanism proposed by Watson, and is modeled in the laboratory not by fear conditioning but by observational learning paradigms. The paradigm may still serve to create aversive associations in the laboratory and investigate the success of various extinction techniques for specific phobias.

Furthermore, specific phobias involve symptoms and behavioural phenomena unobserved in fear conditioning paradigms. Among these are the subjective feeling of anxiety but also of other emotional qualities such as disgust (Olatunji, Armstrong, \& Elwood, 2017), simple passive and active avoidance of a feared object (Beckers, Krypotos, Boddez, Effting, \& Kindt, 2013), and the heterogeneous and sometimes sophisticated safety behaviors exhibited by patients in the presence of a feared object (see Blakey et al. (2019) for an example). A crucial challenge for fear conditioning research will therefore be to model the emergence of behavioral tendencies (Krypotos, 2015) as well as of behaviors that are qualitatively different from what healthy people do: for example, patients with spider phobia tend to avoid looking at a (harmless) spider, but in the presence of a poisonous spider this behavior would be a rather dangerous strategy. Another important example is the presence of intrusive memories in PTSD. These are not usually reported in human fear conditioning (although they are also rarely investigated). More naturalistic setups such as the trauma film paradigm (see Holmes \& Bourne (2008) for a review and Porcheret, Holmes, Goodwin, Foster, \& Wulff (2015) for a contemporary example) experimentally elicit these symptoms. Developing behavioral or neural markers for intrusive memory in these paradigms could help develop more controlled setups that may eventually even be back-translated to nonhuman species. As for specific phobias, it must be emphasized that fear conditioning models cannot (and do not claim) to model all processes or mechanisms involved in complex disorders such as PTSD (see Briscione, Jovanovic, \& Norrholm, 2014). 


\section{Methodological challenges}

Despite apparent similarities in how fear learning is investigated in the laboratory in different species, it is also clear that the translation of fear conditioning findings from other animals to humans faces multiple methodological challenges. For example, rodent and human fear conditioning experiments typically differ in the types of conditioned stimuli (auditory versus mostly visual); the intensity of unconditioned stimuli (typically much lower in human experiments due to ethical constraints); the focus of outcome measures (fear behavior mostly freezing - versus psychophysiological/neural responses/subjective reports); etc. Furthermore, rodent experiments typically use single-cue protocols across multiple days, whereas human experiments mostly use differential-cue protocols conducted in a single day (see Lonsdorf et al., 2017, for a comprehensive review). In addition, data reporting practices and analysis approaches vary considerably across animal (Wotjak, 2019) and human (Lonsdorf et al., 2017) fear conditioning studies, which impacts replicability and generalizablity (see Lonsdorf, Merz, \& Fullana, 2019). As in many fields of clinical neuroscience, a generally accepted measurement-theoretic approach to fear conditioning read-outs is lacking, although initial steps have been taken towards calibrating and optimizing learning measures (Bach et al., 2018b). Addressing these factors will therefore be critical in optimizing the future value of translational research in fear conditioning.

Last but not least, the translation "to the clinic" of fear conditioning models (or treatment techniques based on such models) is often complicated because variables potentially affecting fear-learning processes are typically present in clinical samples. For example, many studies on fear learning in patients with anxiety-related disorders have included patients on medication, but the effects of medication on fear learning processes are 
still not well understood (Singewald et al., 2015). Similarly, most of these studies include patients with comorbid anxiety or depressive disorders, where the effects of comorbidity on fear-learning processes are still also unclear (see Tinoco-Gonzalez et al., 2015).

\section{The need for a "common language"}

Neuroscientists and mental health clinicians have different theoretical approaches, use different methods and, overall, talk different languages. As noted above, fear conditioning models seem to be in an ideal position to bridge the gap (i.e., foster translation) between neuroscience and the clinic. However, for these efforts to be fruitful, a better interdisciplinary communication is needed and efforts need to be made to create or strengthen the links between professionals from both fields. As noted recently, there is a need "to galvanize the next generation of clinical scientists and neuroscientists to interact by creating career opportunities that enable them to experience advanced methods in both" (Holmes, Craske, \& Graybiel, 2014, p. 289).

\section{FUTURE PERSPECTIVES}

\section{Computational approaches}

The idea that alterations in basic fear conditioning and/or extinction contribute to etiology or maintenance of anxiety-related disorders is appealing and has high face validity for clinicians. Nevertheless, studies in controlled laboratory circumstances have so far not been able to identify reproducible characteristic alterations in patient groups. A meta-analysis including over 900 anxiety patients and over 1200 controls has revealed an inconsistent pattern despite the very large sample size (Duits et al., 2015): increased autonomic CS- 
responses in patients during acquisition, but neither increased CS+ responses nor reduced CS+/CS- differences. During extinction, they observed increased CS+ but not CS- responses, and a non-significantly larger CS+/CS- differences. There are certainly many possible reasons for this inconsistency, including publication bias, inadequate laboratory models, measurement problems, and heterogeneous patient populations with insufficient sample sizes in individual studies. One distinct possibility is that a subtly altered fear learning mechanisms can cope well with everyday threats, including the almost trivial punishments used in laboratory research, such that patient/control differences in laboratory research are weak and inconsistent. However, the system may nevertheless break down when pushed to its dynamic limits, leading to the drastic consequences that patients experience.

Indeed, previous studies have mostly investigated patient-control differences in conditioning or extinction over many trials, or explored patient-control differences in linear changes over trials. However, this analysis approach may not reveal subtle alterations in an underlying learning mechanism. For example, a classical learning theory (Rescorla \& Wagner, 1972) would predict that under continuous reinforcement, the trial-by-trial trajectory of learning indices takes an exponential form, where differences in learning rates change the argument of the function. Under partial reinforcement, a learning index would increase by a small amount after reinforcement and decrease by a small amount after non-reinforcement. The magnitude of change after each trial would depend on learning rates and could be different between patients and controls. Taken together, according to this classical view (and other learning theories), altered learning rates would not necessarily lead to pronounced average differences, or different linear change over trials, between patients and controls.

Notably, different learning theories diverge in their predictions how alterations in learning rates play out in the trial-by-trial dynamics of learning indices. However, even in 
healthy humans or animals, these dynamics remain elusive as well. Computational psychology research has only recently begun to scrutinize aversive learning mechanisms. This has revealed that traditional associative learning models (such as the seminal RescorlaWagner (Rescorla \& Wagner, 1972) and Pearce-Hall rules (Pearce \& Hall, 1980)) cannot account for fear conditioning and extinction. To reveal this, at least two approaches are used in the field. First, certain qualitative phenomena (such as backward blocking, latent inhibition, or second-order conditioning) are not compatible with traditional learning models (Gershman, 2015). Notably, it is not fully clear which of these qualitative phenomena can be observed in humans, and by which learning index (see Maes et al., 2016) for failures to observe blocking). The latter point is important because not all learning measures index the same neural learning mechanism. For example, conscious recollection of threat expectation is suggested to index hippocampus-dependent declarative memory rather than amygdaladependent threat memory (Bechara et al., 1995). The second approach is to compare trial-bytrial trajectories of learning to predictions of several learning model, in order to reveal which learning model best explains the data. Again, the choice of learning index plays a crucial role: it is not obvious that all learning indices - even if related to the same learning mechanism relate to the same quantity in the mechanism. For example, skin conductance responses, arguably among the most frequently used human fear conditioning measure, do not appear to relate to US prediction, but rather to some form of uncertainty about this prediction ( $\mathrm{Li}$, Schiller, Schoenbaum, Phelps, \& Daw, 2011; Tzovara, Korn, \& Bach, 2018; Zhang, Mano, Ganesh, Robbins, \& Seymour, 2016).

This line of research has demonstrated that the dynamics of conditioned skin conductance responses are not explained by traditional associative learning models and better explained by a hybrid model combining these two learning models (Li et al., 2011; Tzovara et al., 2018; Zhang et al., 2016). Next, it was suggested that the dynamics of conditioned skin 
conductance and pupil size responses are even better explained by a probabilistic model in which learning decays over time (Tzovara et al., 2018). A probabilistic model can also explain backward blocking and latent inhibition (Gershman, 2015). However, the formulation of the model in Tzovara et al.(2018) does not allow for extinction, and this will require further research. A class of models that can theoretically capture various learning phenomena including extinction and return-of-fear has been suggested under the heading of "latent cause models" (Gershman, Blei, \& Niv, 2010). These learn structure of the environment and its numerical parameters somewhat independently. It remains to be shown under which range of experimental circumstances these models can explain empirical data. The next step will then be to investigate these models in data from patients with anxiety-related disorders.

A century after John Watson and Rosalie Rayner conducted their seminal study, interest in human fear conditioning models remains alive and well among both neuroscientists and clinicians. Although many challenges lay ahead in the translation of conditioning models for the genuine benefit of patient populations, there are many reasons to be optimistic that this research will continue to critically inform the future optimized treatment of anxiety-related disorders. 


\section{ACKNOWLEDGEMENTS}

MAF is supported by Carlos III Health Institute and FEDER grant (PI16/00144). JED is supported in part from NIH R00MH106719 and a National Science Foundation CAREER award (1844792). HSS is supported by an Australian Government Research Training Program (RTP) Scholarship. DRB is supported by funding from the European Research Council (ERC) under the European Union's Horizon 2020 research and innovation programme (Grant agreement No. ERC-2018 CoG-816564 ActionContraThreat). BJH is supported by a NHMRC Career Development Fellowship (1124472), and acknowledges additional funding support from NHMRC Project Grants $(1161897 ; 1145010)$.

\section{CONFLICT OF INTEREST}

The authors declare no conflicts of interest. 


\section{REFERENCES}

Anderson, K. C., \& Insel, T. R. (2006). The Promise of Extinction Research for the Prevention and Treatment of Anxiety Disorders. Biological Psychiatry, 60(4), 319321. https://doi.org/10.1016/j.biopsych.2006.06.022

Apergis-Schoute, A. M., Gillan, C. M., Fineberg, N. A., Fernandez-Egea, E., Sahakian, B. J., \& Robbins, T. W. (2017). Neural basis of impaired safety signaling in Obsessive Compulsive Disorder. Proceedings of the National Academy of Sciences of the United States of America, 114(12), 3216-3221. https://doi.org/10.1073/pnas.1609194114

Bach, D., Brown, S. A., Kleim, B., \& Tyagarajan, S. (2019a). Extracellular matrix: a new player in memory maintenance and psychiatric disorders. Swiss Medical Weekly, 149(21-22). https://doi.org/10.4414/smw.2019.20060

Bach, D. R., Näf, M., Deutschmann, M., Tyagarajan, S. K., \& Quednow, B. B. (2019b). Threat memory reminder under matrix metalloproteinase 9 inhibitor doxycycline globally reduces subsequent memory plasticity. The Journal of Neuroscience, 1285-19. https://doi.org/10.1523/JNEUROSCI.1285-19.2019

Bach, D. R., Weiskopf, N., \& Dolan, R. J. (2011). A Stable Sparse Fear Memory Trace in Human Amygdala. Journal of Neuroscience, 31(25), 9383-9389. https://doi.org/10.1523/JNEUROSCI.1524-11.2011

Bach, D.R., Tzovara, A., \& Vunder, J. (2018a). Blocking human fear memory with the matrix metalloproteinase inhibitor doxycycline. Molecular Psychiatry, 23(7), 15841589. https://doi.org/10.1038/mp.2017.65

Bach, D.R., Castegnetti, G., Korn, C. W., Gerster, S., Melinscak, F., \& Moser, T. (2018b). Psychophysiological modeling: Current state and future directions. Psychophysiology, 
55(11), e13214. https://doi.org/10.1111/psyp.13209

Ball, T. M., Knapp, S. E., Paulus, M. P., \& Stein, M. B. (2017). Brain activation during fear extinction predicts exposure success. Depression and Anxiety, 34(3), 257-266. https://doi.org/10.1002/da.22583

Bechara, A., Tranel, D., Damasio, H., Adolphs, R., Rockland, C., \& Damasio, A. (1995). Double dissociation of conditioning and declarative knowledge relative to the amygdala and hippocampus in humans. Science, 269(5227), 1115-1118. https://doi.org/10.1126/science.7652558

Beckers, T., Krypotos, A.-M. M., Boddez, Y., Effting, M., \& Kindt, M. (2013). What's wrong with fear conditioning? Biological Psychology, 92(1), 90-96. https://doi.org/10.1016/j.biopsycho.2011.12.015

Blakey, S. M., Abramowitz, J. S., Buchholz, J. L., Jessup, S. C., Jacoby, R. J., Reuman, L., \& Pentel, K. Z. (2019). A randomized controlled trial of the judicious use of safety behaviors during exposure therapy. Behaviour Research and Therapy, 112, 28-35. https://doi.org/10.1016/j.brat.2018.11.010

Briscione, M. A., Jovanovic, T., \& Norrholm, S. D. (2014). Conditioned Fear Associated Phenotypes as Robust, Translational Indices of Trauma-, Stressor-, and Anxiety-Related Behaviors. Frontiers in Psychiatry, 5, 88. https://doi.org/10.3389/fpsyt.2014.00088

Brunet, A., Orr, S. P., Tremblay, J., Robertson, K., Nader, K., \& Pitman, R. K. (2008). Effect of post-retrieval propranolol on psychophysiologic responding during subsequent scriptdriven traumatic imagery in post-traumatic stress disorder. Journal of Psychiatric Research, 42(6), 503-506. https://doi.org/10.1016/j.jpsychires.2007.05.006

Brunet, A., Saumier, D., Liu, A., Streiner, D. L., Tremblay, J., \& Pitman, R. K. (2018). 
Reduction of PTSD symptoms with Pre-reactivation propranolol therapy: A randomized controlled trial. American Journal of Psychiatry, 175(5), 427-433. https://doi.org/10.1176/appi.ajp.2017.17050481

Büchel, C., Morris, J., Dolan, R. J., \& Friston, K. J. (1998). Brain Systems Mediating Aversive Conditioning: an Event-Related fMRI Study. Neuron, 20(5), 947-957. https://doi.org/10.1016/S0896-6273(00)80476-6

Bush, D. E. A., Caparosa, E. M., Gekker, A., \& Ledoux, J. (2010). Beta-adrenergic receptors in the lateral nucleus of the amygdala contribute to the acquisition but not the consolidation of auditory fear conditioning. Frontiers in Behavioral Neuroscience, 4 , 154. https://doi.org/10.3389/fnbeh.2010.00154

Cha, J., Greenberg, T., Carlson, J. M., DeDora, D. J., Hajcak, G., \& Mujica-Parodi, L. R. (2014). Circuit-Wide Structural and Functional Measures Predict Ventromedial Prefrontal Cortex Fear Generalization: Implications for Generalized Anxiety Disorder. Journal of Neuroscience, 34(11), 4043-4053. https://doi.org/10.1523/JNEUROSCI.3372-13.2014

Chalah, M. A., \& Ayache, S. S. (2019). Noninvasive Brain Stimulation and Psychotherapy in Anxiety and Depressive Disorders: A Viewpoint. Brain Sciences, 9(4), 82. https://doi.org/10.3390/brainsci9040082

Davis, M., Ressler, K., Rothbaum, B. O., \& Richardson, R. (2006). Effects of D-cycloserine on extinction: translation from preclinical to clinical work. Biological Psychiatry, 60(4), 369-375. https://doi.org/10.1016/j.biopsych.2006.03.084

de Carvalho Myskiw, J., Benetti, F., \& Izquierdo, I. (2013). Behavioral tagging of extinction learning. Proceedings of the National Academy of Sciences of the United States of 
America, 110(3), 1071-1076. https://doi.org/10.1073/pnas.1220875110

Duits, P., Cath, D. C., Lissek, S., Hox, J. J., Hamm, A. O., Engelhard, I. M., ... Baas, J. M. P. (2015). Updated meta-analysis of classical fear conditioning in the anxiety disorders. Depression and Anxiety, 32(4), 239-253. https://doi.org/10.5665/sleep.4802

Dunsmoor, J. E., Kroes, M. C. W., Moscatelli, C. M., Evans, M. D., Davachi, L., \& Phelps, E. A. (2018). Event segmentation protects emotional memories from competing experiences encoded close in time. Nature Human Behaviour, 2(4), 291299. https://doi.org/10.1038/s41562-018-0317-4

Dunsmoor, J. E., Murty, V. P., Davachi, L., \& Phelps, E. A. (2015). Emotional learning selectively and retroactively strengthens memories for related events. Nature, 520(7547), 345-348. https://doi.org/10.1038/nature14106

Eysenck, H. J. (1979). The conditioning model of neurosis. Behavioral and Brain Sciences, 2(2), 155-166. https://doi.org/10.1017/S0140525X00061653

Frey, U., \& Morris, R. G. M. (1997). Synaptic tagging and long-term potentiation. Nature, 385(6616), 533-536. https://doi.org/10.1038/385533a0

Fullana, M. A., Harrison, B. J., Soriano-Mas, C., Vervliet, B., Cardoner, N., Àvila-Parcet, A., ... Radua, J. (2016). Neural signatures of human fear conditioning: an updated and extended meta-analysis of fMRI studies. Molecular Psychiatry, 21(4), 500-508. https://doi.org/10.1038/mp.2015.88

Gershman, S. J. (2015). A Unifying Probabilistic View of Associative Learning. PLOS Computational Biology, 11(11), e1004567. https://doi.org/10.1371/journal.pcbi.1004567

Gershman, S. J., Blei, D. M., \& Niv, Y. (2010). Context, learning, and extinction. 
Psychological Review, 117(1), 197-209. https://doi.org/10.1037/a0017808

Gisquet-Verrier, P., \& Riccio, D. C. (2018). Memory integration: An alternative to the consolidation/reconsolidation hypothesis. Progress in Neurobiology, 171, 15-31. https://doi.org/10.1016/j.pneurobio.2018.10.002

Greenwood, J. D. (1999). Understanding the "cognitive revolution" in psychology. Journal of the History of the Behavioral Sciences, 35(1), 1-22. https://doi.org/10.1002/(SICI)15206696(199924)35:1<1::AID-JHBS1>3.0.CO;2-4

Haaker, J., Gaburro, S., Sah, A., Gartmann, N., Lonsdorf, T. B., Meier, K., ... Kalisch, R. (2013). Single dose of L-dopa makes extinction memories context-independent and prevents the return of fear. Proceedings of the National Academy of Sciences, 110(26), E2428-E2436. https://doi.org/10.1073/pnas.1303061110

Haro, J. M., Ayuso-Mateos, J. L., Bitter, I., Demotes-Mainard, J., Leboyer, M., Lewis, S. W., ... Walker-Tilley, T. (2014). ROAMER: roadmap for mental health research in Europe. International Journal of Methods in Psychiatric Research, 23 Suppl 1, 114. https://doi.org/10.1002/mpr.1406

Haubensak, W., Kunwar, P. S., Cai, H., Ciocchi, S., Wall, N. R., Ponnusamy, R., ... Anderson, D. J. (2010). Genetic dissection of an amygdala microcircuit that gates conditioned fear. Nature. https://doi.org/10.1038/nature09553

Herry, C., \& Johansen, J. P. (2014). Encoding of fear learning and memory in distributed neuronal circuits. Nature Neuroscience, 17(12), 1644-1654. https://doi.org/10.1038/nn.3869

Hofmann, S. G., Otto, M. W., Pollack, M. H., \& Smits, J. A. (2014). D-cycloserine augmentation of cognitive behavioral therapy for anxiety disorders: An update. Current 
Psychiatry Reports, 17(1), 532. https://doi.org/10.1007/s11920-014-0532-2

Hofmann, S. G., Sawyer, A. T., \& Asnaani, A. (2012). D-cycloserine as an augmentation strategy for cognitive behavioral therapy for anxiety disorders: an update. Current Pharmaceutical Design, 18(35), 5659-5662. https://doi.org/10.2174/138161212803530916

Holmes, E. A., \& Bourne, C. (2008). Inducing and modulating intrusive emotional memories: A review of the trauma film paradigm. Acta Psychologica, 127(3), 553-566. https://doi.org/10.1016/j.actpsy.2007.11.002

Insel, T. R. (2014). The NIMH Research Domain Criteria (RDoC) Project: Precision Medicine for Psychiatry. American Journal of Psychiatry, 171(4), 395-397. https://doi.org/10.1176/appi.ajp.2014.14020138

Janak, P. H., \& Tye, K. M. (2015). From circuits to behaviour in the amygdala. Nature, 517(7534), 284-292. https://doi.org/10.1038/nature14188

Johansen, J. P., Cain, C. K., Ostroff, L. E., \& LeDoux, J. E. (2011). Molecular mechanisms of fear learning and memory. Cell, 147(3), 509-524. https://doi.org/10.1016/j.cell.2011.10.009

Jones, M. C. (1924). A Laboratory Study of Fear: The Case of Peter. Pedagogical Seminary, $31,308-315$.

Jovanovic, T., Kazama, A., Bachevalier, J., \& Davis, M. (2012). Impaired safety signal learning may be a biomarker of PTSD. Neuropharmacology. https://doi.org/10.1016/j.neuropharm.2011.02.023

Kazdin, A. E. (1978). Behavior Therapy: Evolution and Expansion. The Counseling 
Psychologist, 7(3), 34-37. https://doi.org/10.1177/001100007800700309

Kindt, M., Soeter, M., \& Vervliet, B. (2009). Beyond extinction: erasing human fear responses and preventing the return of fear. Nature Neuroscience, 12(3), 256258. https://doi.org/10.1038/nn.2271

Krabbe, S., Gründemann, J., \& Lüthi, A. (2018). Amygdala Inhibitory Circuits Regulate Associative Fear Conditioning. Biological Psychiatry. https://doi.org/10.1016/j.biopsych.2017.10.006

Krasner, L. (1990). History of behavior modification. In A. S. Bellack, M. Hersen, \& A. E. Kazdin (Eds.), International Handbook of Behavior Modification and Therapy: Second Edition. Springer.

Krypotos, A.-M. (2015). Avoidance learning: a review of theoretical models and recent developments. Frontiers in Behavioral Neuroscience, 9, 189. https://doi.org/10.3389/fnbeh.2015.00189

LaBar, K S, LeDoux, J. E., Spencer, D. D., \& Phelps, E. A. (1995). Impaired fear conditioning following unilateral temporal lobectomy in humans. The Journal of Neuroscience: The Official Journal of the Society for Neuroscience, 15(10), 6846-6855. Retrieved from http://www.jneurosci.org/content/jneuro/15/10/6846.full.pdf

LaBar, Kevin S, Gatenby, J. C., Gore, J. C., LeDoux, J. E., \& Phelps, E. A. (1998). Human Amygdala Activation during Conditioned Fear Acquisition and Extinction: a MixedTrial fMRI Study. Neuron, 20(5), 937-945. https://doi.org/10.1016/S08966273(00)80475-4

Lange, I., Goossens, L., Leibold, N., Vervliet, B., Sunaert, S., Peeters, R., ... Schruers, K. (2016). Brain and behavior changes following exposure therapy predict outcome at 8- 
year follow-up. Psychotherapy and Psychosomatics, 85(4)., 238-240.

https://doi.org/10.1159/000442292

Lange, I., Goossens, L., Michielse, S., Bakker, J., Vervliet, B., Marcelis, M., ... Schruers, K. (2019). Neural responses during extinction learning predict exposure therapy outcome in phobia: results from a randomized-controlled trial. Neuropsychopharmacology. https://doi.org/10.1038/s41386-019-0467-8

Ledgerwood, L., Richardson, R., \& Cranney, J. (2003). Effects of D-cycloserine on extinction of conditioned freezing. Behavioral Neuroscience, 117(2), 341-9. https://doi.org/10.1037/0735-7044.117.2.341

Ledgerwood, L., Richardson, R., \& Cranney, J. (2005). D-cycloserine facilitates extinction of learned fear: effects on reacquisition and generalized extinction. Biological Psychiatry, 57(8), 841-847. https://doi.org/10.1016/j.biopsych.2005.01.023

LeDoux, J E, Moscarello, J., Sears, R., \& Campese, V. (2017). The birth, death and resurrection of avoidance: a reconceptualization of a troubled paradigm. Molecular Psychiatry, 22(1), 24-36. https://doi.org/10.1038/mp.2016.166

LeDoux, Joseph E. (2014). Coming to terms with fear. Proceedings of the National Academy of Sciences, 111(8), 2871-2878. https://doi.org/10.1073/pnas.1400335111

LeDoux, Joseph E. (2000). Emotion Circuits in the Brain. Annual Review of Neuroscience, 23(1), 155-184. https://doi.org/10.1146/annurev.neuro.23.1.155

Lefaucheur, J.-P., André-Obadia, N., Antal, A., Ayache, S. S., Baeken, C., Benninger, D. H., ... Garcia-Larrea, L. (2014). Evidence-based guidelines on the therapeutic use of repetitive transcranial magnetic stimulation (rTMS). Clinical Neurophysiology, 125(11), 2150-2206. https://doi.org/10.1016/j.clinph.2014.05.021 
Li, J., Schiller, D., Schoenbaum, G., Phelps, E. A., \& Daw, N. D. (2011). Differential roles of human striatum and amygdala in associative learning. Nature Neuroscience, 14(10), 1250-1252. https://doi.org/10.1038/nn.2904

Litz, B. T., Salters-Pedneault, K., Steenkamp, M. M., Hermos, J. A., Bryant, R. A., Otto, M. W., \& Hofmann, S. G. (2012). A randomized placebo-controlled trial of d-cycloserine and exposure therapy for posttraumatic stress disorder. Journal of Psychiatric Research, 46(9), 1184-1190. https://doi.org/10.1016/j.jpsychires.2012.05.006

Lonsdorf, T. B., Menz, M. M., Andreatta, M., Fullana, M. A., Golkar, A., Haaker, J., ... Merz, C. J. (2017). Don’t fear 'fear conditioning': Methodological considerations for the design and analysis of studies on human fear acquisition, extinction, and return of fear. Neuroscience and Biobehavioral Reviews, 77, 247-285. https://doi.org/10.1016/j.neubiorev.2017.02.026

Lonsdorf, T. B., Merz, C. J., \& Fullana, M. A. (2019). Fear Extinction Retention: Is It What We Think It Is? Biological Psychiatry, 85(12), 1074-1082. https://doi.org/10.1016/j.biopsych.2019.02.011

Luyten, L., \& Beckers, T. (2017). A preregistered, direct replication attempt of the retrieval-extinction effect in cued fear conditioning in rats. Neurobiology of Learning and Memory, 144, 208-215. https://doi.org/10.1016/j.nlm.2017.07.014

Mackintosh, N. J. (1974). The psychology of animal learning. Oxford: Academic Press.

Maes, E., Boddez, Y., Alfei, J. M., Krypotos, A.-M., D’Hooge, R., De Houwer, J., \& Beckers, T. (2016). The elusive nature of the blocking effect: 15 failures to replicate. Journal of Experimental Psychology: General, 145(9), e49-e71. https://doi.org/10.1037/xge0000200 
Maren, S., Phan, K. L., \& Liberzon, I. (2013). The contextual brain: implications for fear conditioning, extinction and psychopathology. Nature Reviews. Neuroscience, 14(6), 417-428. https://doi.org/10.1038/nrn3492

Mataix-Cols, D., Fernández de la Cruz, L., Monzani, B., Rosenfield, D., Andersson, E., Pérez-Vigil, A., ... Thuras, P. (2017). D-Cycloserine Augmentation of ExposureBased Cognitive Behavior Therapy for Anxiety, Obsessive-Compulsive, and Posttraumatic Stress Disorders. JAMA Psychiatry, 74(5), 501. https://doi.org/10.1001/jamapsychiatry.2016.3955

McGaugh, J. L. (2015). Consolidating Memories. Annual Review of Psychology, 66(1), 1-24. https://doi.org/10.1146/annurev-psych-010814-014954

Menezes, J., Alves, N., Borges, S., Roehrs, R., de Carvalho Myskiw, J., Furini, C. R. G., ... Mello-Carpes, P. B. (2015). Facilitation of fear extinction by novelty depends on dopamine acting on D1-subtype dopamine receptors in hippocampus. Proceedings of the National Academy of Sciences of the United States of America, 112(13), E1652-8. https://doi.org/10.1073/pnas.1502295112

Milad, M. R., Furtak, S. C., Greenberg, J. L., Keshaviah, A., Im, J. J., Falkenstein, M. J., ... Wilhelm, S. (2013). Deficits in conditioned fear extinction in obsessive-compulsive disorder and neurobiological changes in the fear circuit. JAMA Psychiatry, 70(6), 608-618; quiz 554. https://doi.org/10.1001/jamapsychiatry.2013.914

Milad, M. R., Pitman, R. K., Ellis, C. B., Gold, A. L., Shin, L. M., Lasko, N. B., ... Rauch, S. L. (2009). Neurobiological Basis of Failure to Recall Extinction Memory in Posttraumatic Stress Disorder. Biological Psychiatry, 66(12), 1075-1082. https://doi.org/10.1016/j.biopsych.2009.06.026 
Milad, M. R., \& Quirk, G. J. (2012). Fear extinction as a model for translational neuroscience: ten years of progress. Annual Review of Psychology, 63(1), 129-151. https://doi.org/10.1146/annurev.psych.121208.131631

Moncada, D., \& Viola, H. (2007). Induction of Long-Term Memory by Exposure to Novelty Requires Protein Synthesis: Evidence for a Behavioral Tagging. Journal of Neuroscience, 27(28), 7476-7481. https://doi.org/10.1523/JNEUROSCI.1083-07.2007

Nader, K., Schafe, G. E., \& Le Doux, J. E. (2000). Fear memories require protein synthesis in the amygdala for reconsolidation after retrieval. Nature, 406(6797), 722-726. https://doi.org/10.1038/35021052

Monfils, M. H., \& Holmes, E. A. (2018). Memory boundaries: opening a window inspired by reconsolidation to treat anxiety, trauma-related, and addiction disorders. The Lancet Psychiatry, 5(12), 1032-1042. https://doi.org/10.1016/S2215-0366(18)30270-0

Olatunji, B.O., Armstrong, T., \& Elwood L. (2017). Is disgust proneness associated with anxiety and related disorders? A qualitative review and meta-analysis of group comparison and correlational studies. Perspectives on Psychological Science, 12(4), 613-48. https://doi: 10.1177/1745691616688879.

Parnas, A.S., Weber, M., Richardson, R. (2005). Effects of multiple exposures to D-cycloserine on extinction of conditioned fear in rats. Neurobiology of Learning and Memory, 83(3), 224-31. https://doi.org/10.1016/j.nlm.2005.01.001

Paulus, D. J., Kamboj, S. K., Das, R. K., \& Saladin, M. E. (2019). Prospects for reconsolidationfocused treatments of substance use and anxiety-related disorders. Current Opinion in Psychology, 30, 80-86. ttps://doi.org/10.1016/j.copsyc.2019.03.001 
Pearce, J. M., \& Hall, G. (1980). A model for Pavlovian learning: Variations in the effectiveness of conditioned but not of unconditioned stimuli. Psychological Review, 87(6), 532-552. https://doi.org/10.1037/0033-295X.87.6.532

Phelps, E. A., \& Hofmann, S. G. (2019). Memory editing from science fiction to clinical practice. Nature, 572(7767), 43-50. https://doi.org/10.1038/s41586-019-1433-7

Phelps, E. A., \& LeDoux, J. E. (2005). Contributions of the Amygdala to Emotion Processing: From Animal Models to Human Behavior. Neuron, 48(2), 175-187. https://doi.org/10.1016/j.neuron.2005.09.025

Pitman, R. K., Sanders, K. M., Zusman, R. M., Healy, A. R., Cheema, F., Lasko, N. B., ... Orr, S. P. (2002). Pilot study of secondary prevention of posttraumatic stress disorder with propranolol. Biological Psychiatry, 51(2), 189-192. https://doi.org/10.1016/s00063223(01)01279-3

Porcheret, K., Holmes, E. A., Goodwin, G. M., Foster, R. G., \& Wulff, K. (2015). Psychological Effect of an Analogue Traumatic Event Reduced by Sleep Deprivation. Sleep, 38(7), 1017-1025. https://doi.org/10.5665/sleep.4802

Raij, T., Nummenmaa, A., Marin, M.-F., Porter, D., Furtak, S., Setsompop, K., \& Milad, M. R. (2018). Prefrontal Cortex Stimulation Enhances Fear Extinction Memory in Humans. Biological Psychiatry, 84(2), 129-137. https://doi.org/10.1016/j.biopsych.2017.10.022

Reijmers, L. G., Perkins, B. L., Matsuo, N., \& Mayford, M. (2007). Localization of a Stable Neural Correlate of Associative Memory. Science, 317(5842), 1230-1233. https://doi.org/10.1126/science.1143839

Rescorla, R., \& Wagner, A. . (1972). A theory of Pavlovian conditioning: variations in the effectiveness of reinforcement and nonreinforcement. In A. H. Black \& W. . Prokasky 
(Eds.), Classical conditioniing II: current research and theory (pp. 64-99). New York: Appleton-Century-Crofts.

Ross, D. A., Arbuckle, M. R., Travis, M. J., Dwyer, J. B., van Schalkwyk, G. I., \& Ressler, K. J. (2017). An Integrated Neuroscience Perspective on Formulation and Treatment Planning for Posttraumatic Stress Disorder. JAMA Psychiatry, 74(4), 407. https://doi.org/10.1001/jamapsychiatry.2016.3325

Rothbaum, B. O., Price, M., Jovanovic, T., Norrholm, S. D., Gerardi, M., Dunlop, B., ... Ressler, K. J. (2014). A randomized, double-blind evaluation of D-cycloserine or alprazolam combined with virtual reality exposure therapy for posttraumatic stress disorder in Iraq and Afghanistan War veterans. The American Journal of Psychiatry, 171(6), 640-648. https://doi.org/10.1176/appi.ajp.2014.13121625

Rougemont-Bücking, A., Linnman, C., Zeffiro, T. A., Zeidan, M. A., Lebron-Milad, K., Rodriguez-Romaguera, J., ... Milad, M. R. (2011). Altered processing of contextual information during fear extinction in PTSD: an fMRI study. CNS Neuroscience \& Therapeutics, 17(4), 227-236. https://doi.org/10.1111/j.1755-5949.2010.00152.x

Sartori, S. B., \& Singewald, N. (2019). Novel pharmacological targets in drug development for the treatment of anxiety and anxiety-related disorders. Pharmacology \& Therapeutics, 107402. https://doi.org/10.1016/j.pharmthera.2019.107402

Schiff, H. C., Johansen, J. P., Hou, M., Bush, D. E. A., Smith, E. K., Klein, J. E., ... Sears, R. M. (2017). $\beta$-Adrenergic Receptors Regulate the Acquisition and Consolidation Phases of Aversive Memory Formation Through Distinct, Temporally Regulated Signaling Pathways. Neuropsychopharmacology, 42(4), 895-903. https://doi.org/10.1038/npp.2016.238 
Schwabe, L., Nader, K., \& Pruessner, J. C. (2014). Reconsolidation of Human Memory: Brain Mechanisms and Clinical Relevance. Biological Psychiatry, 76(4), 274-280. https://doi.org/10.1016/j.biopsych.2014.03.008

Sharp, S., Thomas, C., Rosenberg, L., Rosenberg, M., \& Meyer, W. (2010). Propranolol Does Not Reduce Risk for Acute Stress Disorder in Pediatric Burn Trauma. The Journal of Trauma: Injury, Infection, and Critical Care, 68(1), 193-197. https://doi.org/10.1097/TA.0b013e3181a8b326

Singewald, N., Schmuckermair, C., Whittle, N., Holmes, A., \& Ressler, K. J. (2015). Pharmacology of cognitive enhancers for exposure-based therapy of fear, anxiety and trauma-related disorders. Pharmacology \& Therapeutics, 149, 150-190. https://doi.org/10.1016/j.pharmthera.2014.12.004

Smits, J. A. J., Rosenfield, D., Otto, M. W., Powers, M. B., Hofmann, S. G., Telch, M. J., ... Tart, C. D. (2013). D-Cycloserine Enhancement of Fear Extinction is Specific to Successful Exposure Sessions: Evidence from the Treatment of Height Phobia. Biological Psychiatry, 73(11), 1054-1058. https://doi.org/10.1016/j.biopsych.2012.12.009

Staib, M., \& Bach, D. R. (2018). Stimulus-invariant auditory cortex threat encoding during fear conditioning with simple and complex sounds. NeuroImage, 166, 276-284. https://doi.org/10.1016/j.neuroimage.2017.11.009

Suarez-Jimenez, B., Albajes-Eizagirre, A., Lazarov, A., Zhu, X., Harrison, B. J., Radua, J., ... Fullana, M. A. (2019). Neural signatures of conditioning, extinction learning, and extinction recall in posttraumatic stress disorder: a meta-analysis of functional magnetic resonance imaging studies. Psychological Medicine, 1-10. 
https://doi.org/10.1017/S0033291719001387

Tinoco-González, D., Fullana, M. A., Torrents-Rodas, D., Bonillo, A., Vervliet, B., Blasco, M. J., ... Torrubia, R. (2015). Conditioned Fear Acquisition and Generalization in Generalized Anxiety Disorder. Behavior Therapy, 46(5), 627-639. https://doi.org/10.1016/j.beth.2014.12.004

Tovote, P., Fadok, J. P., \& Lüthi, A. (2015). Neuronal circuits for fear and anxiety. Nature Reviews Neuroscience, 16(6), 317-331. https://doi.org/10.1038/nrn3945

Treanor, M., Brown, L. A., Rissman, J., \& Craske, M. G. (2017). Can Memories of Traumatic Experiences or Addiction Be Erased or Modified? A Critical Review of Research on the Disruption of Memory Reconsolidation and Its Applications. Perspectives on Psychological Science, 12(2), 290-305. https://doi.org/10.1177/1745691616664725

Tzovara, A., Korn, C. W., \& Bach, D. R. (2018). Human Pavlovian fear conditioning conforms to probabilistic learning. PLoS Computational Biology, 14(8), e1006243. https://doi.org/10.1371/journal.pcbi.1006243

Veit, R., Flor, H., Erb, M., Hermann, C., Lotze, M., Grodd, W., \& Birbaumer, N. (2002). Brain circuits involved in emotional learning in antisocial behavior and social phobia in humans. Neuroscience Letters, 328(3), 233-236. https://doi.org/10.1016/S03043940(02)00519-0

Via, E., Fullana, M. A., Goldberg, X., Tinoco-González, D., Martínez-Zalacaín, I., SorianoMas, C., ... Harrison, B. J. (2018). Ventromedial prefrontal cortex activity and pathological worry in generalised anxiety disorder. British Journal of Psychiatry,213(1), 437-443. https://doi.org/10.1192/bjp.2018.65 
Visser, R. M., Scholte, H. S., Beemsterboer, T., \& Kindt, M. (2013). Neural pattern similarity predicts long-term fear memory. Nature Neuroscience, 16(4), 388-390. https://doi.org/10.1038/nn.3345

Weiskopf, N., Hutton, C., Josephs, O., \& Deichmann, R. (2006). Optimal EPI parameters for reduction of susceptibility-induced BOLD sensitivity losses: a whole-brain analysis at 3 T and 1.5 T. NeuroImage, 33(2), 493-504. https://doi.org/10.1016/j.neuroimage.2006.07.029

Wolpe, J. (1961). The systematic desensitization treatment of neuroses. The Journal of Nervous and Mental Disease, 132(3), 189-203. https://doi.org/10.1097/00005053196103000-00001

Wood, N. E., Rosasco, M. L., Suris, A. M., Spring, J. D., Marin, M.-F., Lasko, N. B., ... Pitman, R. K. (2015). Pharmacological blockade of memory reconsolidation in posttraumatic stress disorder: Three negative psychophysiological studies. Psychiatry Research, 225(1-2), 31-39. https://doi.org/10.1016/j.psychres.2014.09.005

Zhang, S., Mano, H., Ganesh, G., Robbins, T., \& Seymour, B. (2016). Dissociable Learning Processes Underlie Human Pain Conditioning. Current Biology, 26(1), 52-58. https://doi.org/10.1016/j.cub.2015.10.066 